\title{
BIRCH PLYWOOD SAMPLE TENSION AND BENDING PROPERTY INVESTIGATION AND VALIDATION IN SOLIDWORKS ENVIRONMENT
}

\author{
Agris Zalcmanis ${ }^{1}$, Kaspars Zudrags' ${ }^{1}$, Guntis Japiṇš² \\ ${ }^{1}$ AS “Latvijas Finieris”, Latvia \\ ${ }^{2}$ Riga Technical University, Latvia \\ agris.zalcmanis@finieris.lv
}

\begin{abstract}
Birch plywood has proved itself to be one of the most rational ways of wood processing. Growing demand of high performance birch plywood products requires a complex numerical analysis based on Finite Element Method (FEM), instead of using simple analytical assumptions, which prevent optimization of plywood construction (lay-up). In the research samples of birch plywood of several thicknesses, both sanded and non-sanded, with fiber direction of external veneer both in the longitudinal and transverse directions were tested. An extensometer and optical strain gauge were used for strain measurement. The FEM analysis, using commercial software SolidWorks Simulation Premium (SW), versus experimental bending and tension testing according to LVS EN 789 was carried out in this paper.

The analysis of results indicates that there is a high correlation between the results of the experiments and the FEM. Particularly for in tension loaded specimens one can be tested up to the maximum ply strength (100 MPa); meanwhile, in bending up to $71 \mathrm{MPa}$ - the average stress in load bearing ply at the proportionality limit. Due to software restrictions, shear stresses cannot be evaluated. Future studies are considered to investigate terms for designing plywood with dynamic properties of strength and stiffness to be taken into account.
\end{abstract}

Key words: plywood, modulus of elasticity, tension, bending, shear.

\section{Introduction}

Birch (Betula $s p$.) is species of wood typically found in Eurasia and a second widespread breed in Latvia, reaching 30.9\% (Latvian Forest Sector, 2017). Birch is considered as hardwood and has excellent mechanical properties due to which it has a huge economical potential. Nowadays birch is also one of the main species (38\%) used for afforestation of former agricultural lands (Jansons et al., 2011). Furthermore, the gain of birch plantations might be substantially improved by breeding (Zeltinš et al., 2018) to satisfy a growing demand for birch products like lumber, sawn timber and plywood.

Plywood is considered a layered cross-ply unidirectional fiber reinforced composite produced from veneers with a fiber direction perpendicular to each other. A typical usage of birch plywood is found in automotive (trailer floors, wall linings) and construction industry (concrete formworks). Plywood is also used for yacht building, as insulation panels in liquid natural gas tankers, furniture, builders' carpentry and joinery and many others. In automotive, yacht building and sea transport industry analytical calculations of plywood load bearing capacity and stiffness must be carried out.

Common praxis is to use simple analytical assumptions in design of plywood or plywood constructions. Unfortunately, the use of such a method restricts application of plywood as a contemporary construction material, prevents optimization of its construction (lay-up) and evaluation of stresses in the material at complex stress states. Computer simulations based on the finite element method (FEM) are now fundamental design practices in a number of high performance industries like aerospace and aviation. Meanwhile, other industries are beginning to evaluate the benefits of FEM analysis and use it to develop innovative solutions.

To develop a reliable design method using FEM, it is necessary to determine characteristics of plywood experimentally and validate FEM design guidelines. In the research samples of birch plywood of several thicknesses, sanded and non-sanded, with the fiber direction of external veneer in the longitudinal and transverse directions were tested. Tensile and bending tests were conducted according to LVS EN 789. Both the extensometer and optical strain gauge were used for strain measurement. The shear modulus and the global elastic modulus in bending were calculated in accordance with LVS EN 408. Analysis and validation of the obtained data indicate that there is a correlation between the results of the experiments and the FEM.

This paper presents validation of FEM design method versus experimental bending and tension testing for birch plywood in commercial software SolidWorks.

\section{Materials and Methods}

In order to elaborate the FEM design method, the analysis was performed for all panel thicknesses in the range from 4 to $50 \mathrm{~mm}$ manufactured from birch and glued with phenol formaldehyde resin. Restrictions for thickness analysis:

- All veneers including outer plies before sanding must be of the same thickness;

- Thickness of plywood made from virtual plies must be as close as possible to the average thickness of actual product in a range as wide as possible. 
The following assumptions are made:

- Mechanical properties of layers in same direction are identical;

- A glue layer between plies is omitted;

- Sanding is symmetric from both sides;

- Only variable to comprehend actual thickness for particular specimen is sanding depth.

Modeling plywood with a different ply thickness and sanding depth showed that the ply thickness 1.43 $\mathrm{mm}$ and sanding depth $0.4 \mathrm{~mm}$ from each side show the most adequate correlation between actual and virtual models in the widest range. Table 1 shows thicknesses and lay-ups of test specimens used in the FEM method validation.

Table 1

Lay-up and average thickness of specimens

\begin{tabular}{|l|c|c|c|}
\hline Designation & Lay-up & $\begin{array}{c}\text { Thickness } \\
\text { for virtual } \\
\text { testing } \\
\text { (sanded) } \\
\text { (mm) }\end{array}$ & $\begin{array}{c}\text { Thickness for } \\
\text { virtual testing } \\
\text { (non-sanded) } \\
\text { (mm) }\end{array}$ \\
\hline $12-0$ & I-I-I-I-I & 12.07 & 12.87 \\
\hline $12-90$ & -I-I-I-I- & 12.07 & 12.87 \\
\hline $18-0$ & I-I-I-I-I-I-I & 17.79 & 18.59 \\
\hline $18-90$ & -I-I-I-I-I-I- & 17.79 & 18.59 \\
\hline
\end{tabular}

SolidWorks Premium (Service pack 4.1; Dassault Systemes, 2017) with Simulation Premium package (2017) was used for virtual testing. Plywood is modeled as solid consisting of bodies which represent mechanical properties of ply (table 2) (Labans et al., 2017). The material is linear elastic orthotropic, contact type between plies is 'bonded'- no slippage or delamination, entities behave as if they were welded ('Bonded contact', 2017). Solid mesh is 'compatible'the program merges coincident nodes along the interface ('Compatible', 2017).

Table 2

\section{Mechanical properties of birch ply}

\begin{tabular}{|l|c|}
\hline \multicolumn{1}{|c|}{ Property } & Value \\
\hline Longitudinal modulus & $17 \mathrm{GPa}$ \\
\hline Transverse modulus & $0.5 \mathrm{GPa}$ \\
\hline Shear modulus & $0.7 \mathrm{GPa}$ \\
\hline Poisson's ration & 0.35 \\
\hline Poisson's ration & 0.01 \\
\hline Longitudinal strength & $100 \mathrm{MPa}$ \\
\hline Transverse strength & $4 \mathrm{MPa}$ \\
\hline
\end{tabular}

Eighty eight (8 groups, 11 specimen in series) tensile test and forty eight (8 groups, 6 specimen in series) bending test specimens from birch plywood were manufactured. Samples were cut from various panels. Specimens cut from the same panel were marked. Tensile and bending tests were conducted according to LVS EN 789. A contact extensometer was used in tensile tests to measure displacement of both outer layers, measuring the span $100 \mathrm{~mm}$, an extensometer was placed symmetrically in the middle. During the test outer plies of specimen are clamped with hydraulic jaws. Authors are concerned that especially for plywood with load bearing outer plies direct contact with jaws could cause inaccuracy in measurements and furthermore in calculations of modulus of elasticity. Hypothesis is put forward that outer plies deform more than core plies. Figure 1 shows a possible distribution of displacement through thickness. Optical strain gauge with tracking points on core plies was used in order to estimate difference between ply displacements along the thickness of the sample.

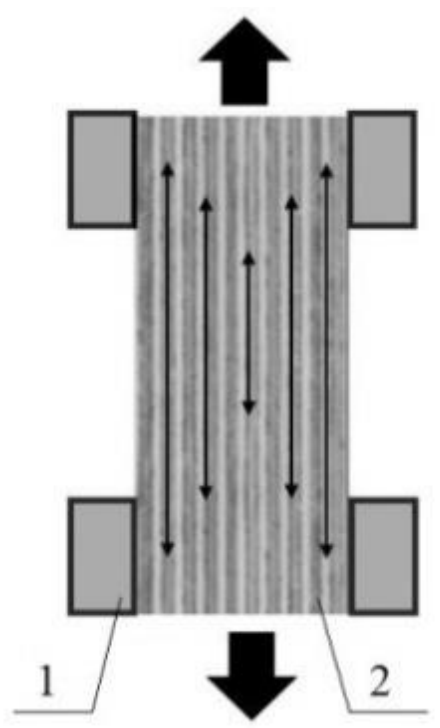

Figure 1. Distribution of displacement through thickness in tensile test.

(1 - jaws; 2 - test specimen).

In four-point bending test specimen dimensions are dependent on thickness. The span length is calculated according to the nominal thickness regardless of the surface condition. For samples with the nominal thickness $12 \mathrm{~mm}$ span length is $684 \mathrm{~mm}$ and the overall sample length is $884 \mathrm{~mm}$, for samples with the nominal thickness $18 \mathrm{~mm}-876 \mathrm{~mm}$ and 1,076 mm. The distance between loading points is $300 \mathrm{~mm}$.

During the test the local deflection on the compression side of panel (top) and the global deflection on the tension side of panel (bottom) of bending was measured with two high precision plunger type extensometers located in the middle of 
the span. The local modulus of elasticity in bending was calculated according to LVS EN 789. The global modulus of elasticity in bending was calculated according to LVS EN 408. Values calculated according to LVS EN 408 cannot be used for calculations of characteristic values. Shear deformation of the layers in the vicinity of the support was measured according to LVS EN 408 shear field test method as it allows collecting all the necessary data together with the determination of the bending strength and global modulus of elasticity. LVS EN 789, in contrast, requires special specimens and loading equipment. Optical strain gauge with four tracking points forming a square was used for the shear deformation measurement (Figure 2).
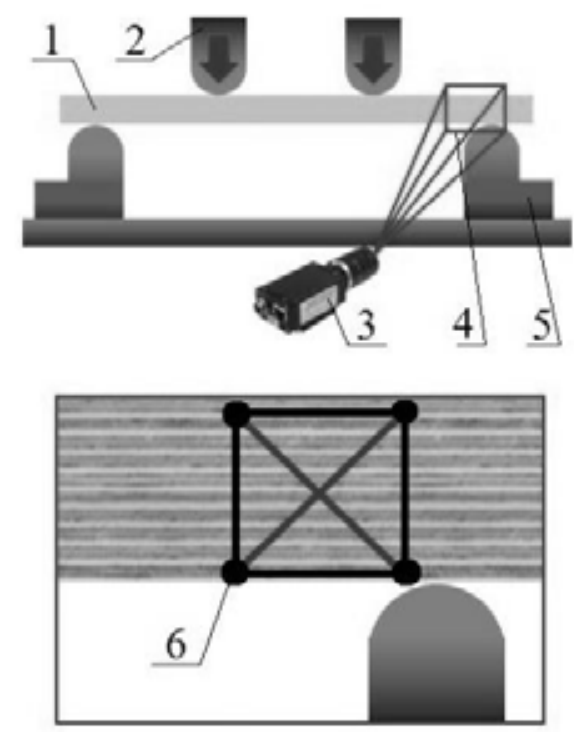

Figure 2. Four-point bending test arrangement with shear deformation measuring.

( 1 - test specimen; 2 - loading bars; 3 - optical strain gauge; 4 - vision field of camera; 5 - support bars; 6 - tracking points).

Attempts were made to measure the permanent deformation to determine the limit of elasticity. An optical strain gauge with one tracking point in the middle of the span was used to obtain a deflectionforce curve during relief of the specimen.

Statistical processing of obtained data was performed, the modulus of elasticity in tension and bending was calculated as well as a planar shear modulus in bending. A virtual testing of specimens with the same geometric parameters was carried out. Strain-stress curves were plotted to validate numerical results with experimental.

\section{Results and Discussion}

Obtained numerical calculations and experimental results are in a good agreement confirming that input values for the ply thickness and mechanical properties describe birch plywood under bending and tensile loads relatively well.

The rupture in tension for almost all specimens regardless of fiber orientation in the outer ply happened along the line where a fillet started. A minor part of specimens ruptured in the uniform stress zone. The rupture near jaws or in the fillet zone was not observed. The stress concentrator in exactly the same place can be seen in FEM model (Figure 3). 12mm0 -unsanded maximum stress in ply reaches $125 \mathrm{MPa}$, while the average stress across the cross section of ply is $103 \mathrm{MPa}$. The average stress in the vicinity of fillet is equal with the average stress in the uniform stress zone.

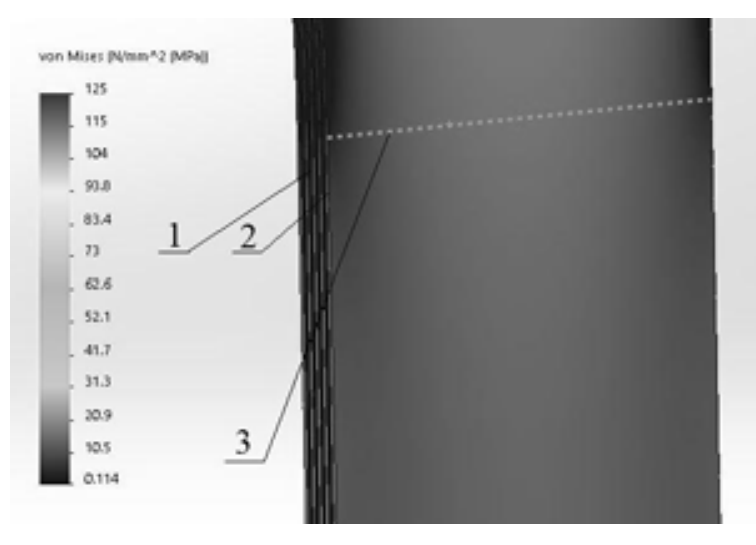

Figure 3. Stress distribution in FEM model.

( 1 - non load bearing veneer; 2 - load bearing veneer; 3 fillet starting zone).

Strain measurement parameters used in the experiment were reproduced in a virtual test with tracking points on outer surfaces. LVS EN 1058 allows using mean values of modulus of elasticity from series as a characteristic value. The mean thickness of plywood will be used for the FEM method validation. Figure 4 shows an example of the load-deflection curve obtained from the test and virtual test. It is clearly visible that the load-elongation curve is linear up to the rupture. Summary of test results for all specimen groups are shown in Table 3 and Table 4.

Capturing of individual ply displacement is continued up to the rupture. Regardless of the surface condition of outer ply - sanded or non-sanded, with fiber direction parallel or perpendicular, it deforms more than core plies. The hypothesis is partly confirmed. There is a noticeable difference between strains among plies. The summary of results for specimen groups is shown in Table 5.

Results indicate that thicker panels are having bigger differences in the outer and core ply strain. 12 mm panels regardless of surface condition of the outer ply - sanded or non-sanded, with a fiber direction 

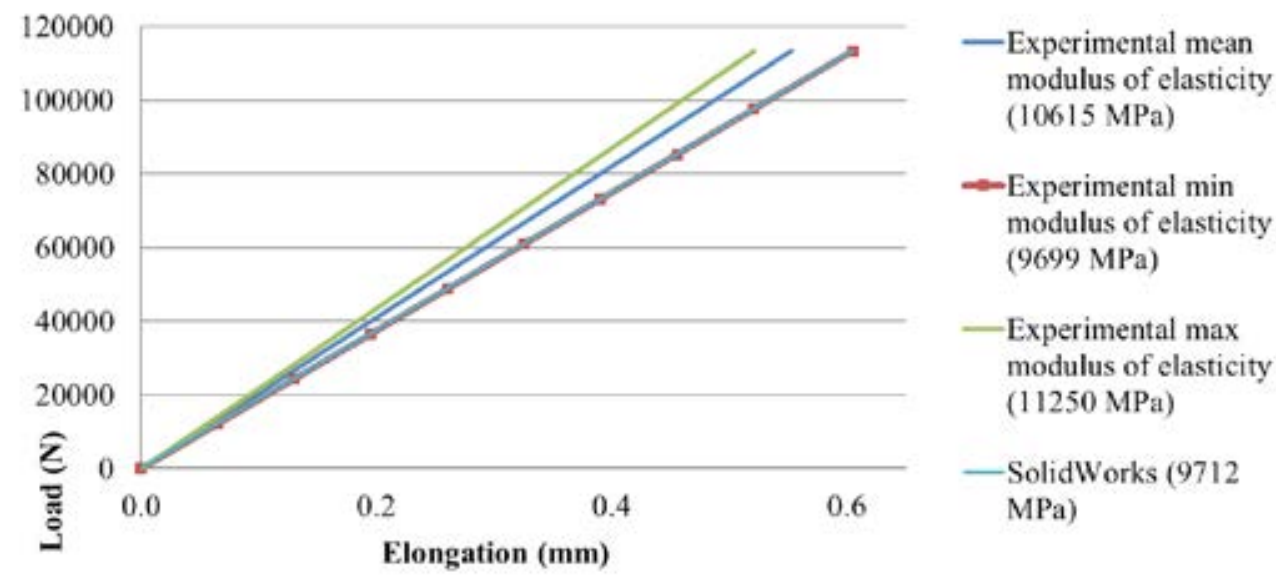

Figure 4. Load-elongation curve for 12mm-0-unsanded plywood.

Table 3

\section{Results of tensile test}

\begin{tabular}{|l|c|c|c|c|c|c|c|c|}
\hline $\begin{array}{c}\text { Specimen } \\
\text { designation }\end{array}$ & $\begin{array}{c}\text { Average } \\
\text { stress } \\
\sigma_{\text {avg }} \\
\text { (MPa) }\end{array}$ & $\begin{array}{c}\text { Standard } \\
\text { deviation } \\
S \\
\text { (MPa) }\end{array}$ & $\begin{array}{c}\text { CV } \\
(\%)\end{array}$ & $\begin{array}{c}\text { Min } \\
\text { stress } \\
\text { (MPa) }\end{array}$ & $\begin{array}{c}\text { Allowable } \\
\text { design stress } \\
\sigma_{\text {avg }}-2 * S \\
\text { (MPa) }\end{array}$ & $\begin{array}{c}\text { Tension strength } \\
\text { (Plywood } \\
\text { Handbook, 2017) } \\
\text { (MPa) }\end{array}$ & $\begin{array}{c}\text { Average } \\
\text { stress in load } \\
\text { bearing ply } \\
\text { from SW } \\
\text { (MPa) }\end{array}$ & $\begin{array}{c}\text { Max stress in } \\
\text { load bearing } \\
\text { ply from SW } \\
\text { (MPa) }\end{array}$ \\
\hline $\begin{array}{l}\text { 12mm-0- } \\
\text { unsanded }\end{array}$ & 58.7 & 5.6 & 9.5 & 50.5 & 47.6 & 43.3 & 103 & 125 \\
\hline $\begin{array}{l}\text { 12mm-90- } \\
\text { unsanded }\end{array}$ & 53.3 & 5.0 & 9.4 & 45.7 & 43.3 & 34.7 & 115 & 136 \\
\hline $\begin{array}{l}\text { 12mm-0- } \\
\text { sanded }\end{array}$ & 50.5 & 8.5 & 16.8 & 40.3 & 33.5 & 41.6 & 93.5 & 113 \\
\hline $\begin{array}{l}\text { 12mm-90- } \\
\text { sanded* }\end{array}$ & 57.6 & 1.5 & 2.6 & 56.6 & 54.6 & 36.4 & 117 & 139 \\
\hline $\begin{array}{l}\text { 18mm-0- } \\
\text { unsanded }\end{array}$ & 55.8 & 5.1 & 9.2 & 48.5 & 45.5 & 42.0 & 106 & 129 \\
\hline $\begin{array}{l}18 m m-90- \\
\text { unsanded* }\end{array}$ & 44.0 & 0.9 & 2.0 & 43.0 & 42.2 & 36.0 & 92 & 109 \\
\hline $\begin{array}{l}18 m m-0- \\
\text { sanded }\end{array}$ & 57.3 & 3.9 & 6.9 & 52.2 & 49.4 & 40.8 & 107 & 130 \\
\hline $\begin{array}{l}18 m m-90- \\
\text { sanded }\end{array}$ & 49.9 & 5.0 & 10.0 & 41.6 & 39.9 & 37.2 & 100 & 119 \\
\hline
\end{tabular}

*Samples taken out of stress analysis due to errors. Remaining samples are from the same panel.

parallel or perpendicular got the average disparity of $0.0005 \mathrm{~mm} / \mathrm{mm}$, meanwhile $18 \mathrm{~mm}$ panels 0.0011 $\mathrm{mm} / \mathrm{mm}$. The difference of plywood panels thickness used in tests is 1.5 times, but the difference of average disparity -2.2 .

Due to restrains in testing equipment and large deflections of specimen, it was impossible to evaluate the bending failure strength. Therefore, specimens were tested only up to the maximum deflection possible in the testing set-up. The global and local modulus of elasticity in bending was calculated. Permanent deformation was observed. Four out of six specimens in series were used to evaluate shear modulus in the shear field (LVS, 2011), two were used for the measurement of permanent deformation.

Results shown in Table 6 prove that the shear field test method developed for structural and laminated timber can be used for the shear deformation measurement also for wooden cross-ply - plywood.

Unfortunately, interlaminar shear stress components do not apply for bodies defined as orthotropic materials ( 'Composite Laminate', 2017) for current SolidWorks Simulation Professional license, values obtained from the ply relative displacement 


\section{Results of tensile test}

\begin{tabular}{|c|c|c|c|c|c|c|}
\hline $\begin{array}{l}\text { Specimen } \\
\text { designation }\end{array}$ & $\begin{array}{l}\text { Average } \\
\text { modulus of } \\
\text { elasticity } \\
E_{t ; a v g} \\
(\mathrm{MPa})\end{array}$ & $\begin{array}{c}\text { Min } \\
\text { modulus of } \\
\text { elasticity } \\
E_{t ; \min } \\
(\mathrm{MPa})\end{array}$ & $\begin{array}{c}\text { Max } \\
\text { modulus of } \\
\text { elasticity } \\
E_{t ; \max } \\
(\mathrm{MPa})\end{array}$ & $\begin{array}{c}\text { Elastic } \\
\text { modulus } \\
\text { from SW } \\
E_{t ; S W} \\
(\mathrm{MPa})\end{array}$ & $\begin{array}{c}\left(E_{t ; S W} / E_{t ; a v g}\right)-1 \\
(\%)\end{array}$ & $\begin{array}{c}\text { Elastic modulus } \\
\text { in tension } \\
\text { (Plywood } \\
\text { Handbook, } \\
\text { 2017) (MPa) }\end{array}$ \\
\hline 12mm-0-unsanded & 10615 & 9699 & 11250 & 9712 & -8.5 & 10000 \\
\hline 12mm-90-unsanded & 8881 & 7777 & 10639 & 7838 & -11.7 & 8000 \\
\hline 12mm-0-sanded & 9108 & 7625 & 10113 & 9182 & 0.8 & 9600 \\
\hline 12mm-90-sanded & 8168 & 6788 & 10193 & 8342 & 2.2 & 8400 \\
\hline 18mm-0-unsanded & 9789 & 9231 & 10326 & 9000 & -8.1 & 9692 \\
\hline 18mm-90-unsanded & 8753 & 7919 & 10163 & 8148 & -6.9 & 8308 \\
\hline 18mm-0-sanded & 10554 & 9416 & 12260 & 9095 & -13.8 & 9409 \\
\hline 18mm-90-sanded & 8846 & 8058 & 10163 & 8458 & -4.4 & 8591 \\
\hline
\end{tabular}

\section{Strain at rupture among plies}

\begin{tabular}{|l|c|c|c|}
\hline \multicolumn{1}{|c|}{ Specimen designation } & Average strain of core ply & Average strain of outer ply & Average strain SW \\
\hline $12 \mathrm{~mm}-0$-unsanded & 0.0062 & 0.0067 & 0.0064 \\
\hline $12 \mathrm{~mm}-90$-unsanded & 0.0069 & 0.0075 & 0.0068 \\
\hline $12 \mathrm{~mm}-0$-sanded & 0.0057 & 0.0062 & 0.0055 \\
\hline $12 \mathrm{~mm}-90$-sanded* & - & - & 0.0069 \\
\hline $18 \mathrm{~mm}-0$-unsanded & 0.0054 & 0.0066 & 0.0062 \\
\hline $18 \mathrm{~mm}-90$-unsanded* & - & - & 0.0054 \\
\hline $18 \mathrm{~mm}-0$-sanded & 0.0050 & 0.0059 & 0.0063 \\
\hline $18 \mathrm{~mm}-90$-sanded & 0.0056 & 0.0069 & 0.0059 \\
\hline
\end{tabular}

test in tension and shear field test in bending cannot be validated. Lack of shear deformation will cause an inaccuracy in measurements for thick plywood panels.

Figure 5 shows an example of load-deflection curve obtained from the test. It is clearly visible that a load-elongation curve is linear up to the proportional limit, followed by the non-linear stiffness decrease.
Linear approximation is used to approximate elastic modulus in bending after the proportional limit. Elastic deformation is calculated according to formula:

$$
w_{e}=w_{t o t}-w_{\text {perm }},
$$

where: - total deflection $(\mathrm{mm}), \quad-$ permanent deformation.

\section{Planar shear modulus}

\begin{tabular}{|l|c|c|}
\hline \multicolumn{1}{|c|}{ Specimen designation } & $\begin{array}{c}\text { Planar shear modulus } \\
G_{\text {tor }, \text { }}(\mathrm{MPa})\end{array}$ & $\begin{array}{c}\text { Planar shear modulus } \\
\text { (Plywood Handbook, 2017) (MPa) }\end{array}$ \\
\hline $12 \mathrm{~mm}-0$-unsanded & 240 & 192 \\
\hline $12 \mathrm{~mm}-90$-unsanded & 198 & 149 \\
\hline $12 \mathrm{~mm}-0$-sanded & 140 & 190 \\
\hline $12 \mathrm{~mm}-90$-sanded & 171 & 156 \\
\hline $18 \mathrm{~mm}-0$-unsanded & 184 & 162 \\
\hline $18 \mathrm{~mm}-90$-unsanded & 242 & 189 \\
\hline $18 \mathrm{~mm}-0$-sanded & 174 & 168 \\
\hline $18 \mathrm{~mm}-90$-sanded & 182 & \\
\hline
\end{tabular}




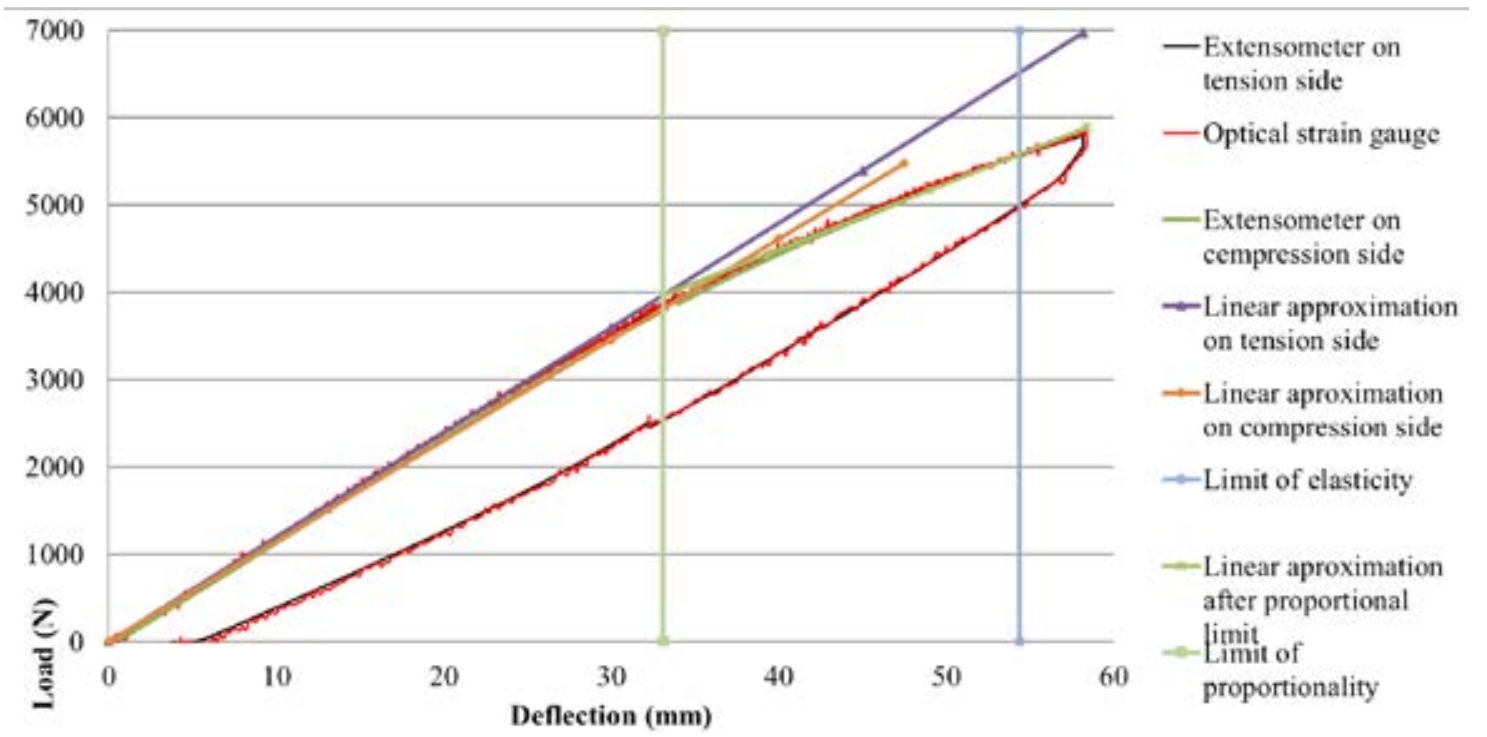

Figure 5. Load-deflection curve for the $12 \mathrm{~mm}-0$-unsanded plywood.

Table 7

\section{Results of four-point bending test}

\begin{tabular}{|l|c|c|c|c|c|}
\hline \multicolumn{1}{|c|}{$\begin{array}{c}\text { Specimen } \\
\text { designation }\end{array}$} & $\begin{array}{c}\text { Average modulus } \\
\text { of elasticity up to } \\
\text { proportional limit } \\
E_{b ; \text {; }} \\
(\mathrm{MPa})\end{array}$ & $\begin{array}{c}\text { Average modulus } \\
\text { of elasticity up to } \\
\text { proportional limit } \\
\text { with shear } E_{b, g ; \text { avg }} \\
(\mathrm{MPa})\end{array}$ & $\begin{array}{c}\text { Elastic } \\
\text { modulus from } \\
\text { SW } E_{b ; S W} \\
(\mathrm{MPa})\end{array}$ & $\begin{array}{c}\left(E_{b ; S W} / E_{b ; \text { avg }}\right) \\
(\%)\end{array}$ & $\begin{array}{c}\text { Elastic modulus in } \\
\text { bending }(\text { Plywood } \\
\text { Handbook, 2017) } \\
(\mathrm{MPa})\end{array}$ \\
\hline $12 \mathrm{~mm}-0$-unsanded & 11762 & 12072 & 11444 & -2.7 & 11975 \\
\hline $12 \mathrm{~mm}-90$-unsanded & 6340 & 6464 & 6093 & -3.9 & 6025 \\
\hline $12 \mathrm{~mm}-0$-sanded & 10423 & 10874 & 10426 & 0.0 & 11026 \\
\hline $12 \mathrm{~mm}-90$-sanded & 8372 & 8496 & 7280 & -13.0 & 6974 \\
\hline $18 \mathrm{~mm}-0$-unsanded & 10888 & 11692 & 10332 & -5.1 & 11069 \\
\hline $18 \mathrm{~mm}-90$-unsanded & 7276 & 7375 & 6648 & -8.6 & 6931 \\
\hline $18 \mathrm{~mm}-0$-sanded & 10097 & 10454 & 9470 & -6.2 & 10335 \\
\hline $18 \mathrm{~mm}-90$-sanded & 8156 & 8472 & 7532 & -7.6 & 7665 \\
\hline
\end{tabular}

\section{Results of four-point bending test}

Table 8

\begin{tabular}{|l|c|c|c|}
\hline $\begin{array}{c}\text { Specimen } \\
\text { designation }\end{array}$ & $\begin{array}{c}\text { Average modulus of elasticity } \\
\text { after proportional limit } E_{b ; \text { avg }}^{\prime} \\
(\mathrm{MPa})\end{array}$ & $\begin{array}{c}\text { Average stress in outer load bearing } \\
\text { ply at proportional limit from SW } \\
(\mathrm{MPa})\end{array}$ & $\begin{array}{c}\left(E_{b ; \text { avg }}^{\prime} / E_{\text {b; avg }}\right)-1 \\
(\%)\end{array}$ \\
\hline $12 \mathrm{~mm}-0$-unsanded & 7265 & 74.4 & -38.2 \\
\hline $12 \mathrm{~mm}-90$-unsanded & 3655 & 75.2 & -42.3 \\
\hline $12 \mathrm{~mm}-0$-sanded & 6303 & 70.4 & -39.5 \\
\hline $12 \mathrm{~mm}-90$-sanded & 5057 & 74.0 & -39.6 \\
\hline $18 \mathrm{~mm}-0$-unsanded & 5542 & 72.3 & -49.1 \\
\hline $18 \mathrm{~mm}-90$-unsanded & 3791 & 67.8 & -47.9 \\
\hline $18 \mathrm{~mm}-0$-sanded & 6026 & 68.3 & -40.3 \\
\hline $18 \mathrm{~mm}-90$-sanded & 3751 & 64.2 & -54.0 \\
\hline
\end{tabular}


From the relief curve it is visible that if it cannot be approximated with the line parallel to loading up to the proportional limit, bending has caused a damage in the material. Stiffness degradation has happened. The summary of test results for all specimen groups are shown in Table 7 and Table 8. As there are no shear deformations in SolidWorks, global modulus of elasticity in bending for the FEM method validation will be calculated with the infinite shear modulus (LVS, 2011). Deflection measurement parameters used in the experiment were reproduced in the virtual test with tracking points on outer surfaces. Figure 6 shows the stress distribution in test specimen. As expected, there is an equal and truly uniform stress zone between lines where the load is applied on a tension and compression side. Modulus of elasticity is strongly dependent on the thickness because in calculations it is in third order. For this reason virtual tests were carried out for every particular specimen, with adapted sanding depth to match thickness with corresponding test sample, only then mean values were calculated.

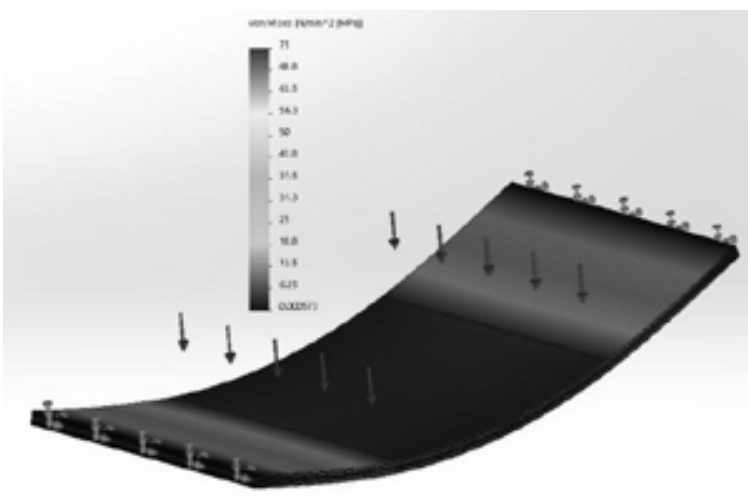

Figure 6. Stress distribution in bending for $12 \mathrm{~mm}-0$ unsanded plywood.

Results of tensile and bending tests show that elastic modulus obtained from SW is $6.1 \%$ smaller than the one obtained from the experiment. It means that actual deformations of plywood or its structures will be smaller than calculated. The average stress in the outer load bearing ply at the proportional limit from SW bending test simulations is 70.8 MPa. After that point $-43.9 \%$ average decrease of modulus of elasticity in bending is predicted. According to the research protocol of VTT, the mean tension strength of ply is $109 \mathrm{MPa}$, the characteristic value is $78 \mathrm{MPa}$. These values correlate with ones obtained from the experiment and virtual test - $104 \mathrm{MPa}$ and $87 \mathrm{MPa}$ respectively, although the average maximum stress in load bearing ply is $125 \mathrm{MPa}$.

Deformations in tensile tests are very small, thus hard to measure. The deflection in bending is roughly 15-20 times absolute elongation in tension, thus easy to measure. A small error in measuring deflection does not cause a significant error in calculations. The problem in tension is that the outer fiber is responsible for the relative deformation of the outer layers. The more sanded the ply is, the more disperse measurements it can cause. Also, a direct contact with jaws of loading equipment for plywood with load bearing outer plies causes an inaccuracy in measurements and furthermore in calculations of modulus of elasticity.

\section{Conclusions}

1. The FEM design method elaborated and validated in this paper can be used for virtual testing of birch plywood in SW environment ( in bending tests, in tension tests), although for bending tests model used here is valid only for linearly elastic region up to the proportionality limit.

2. More tests need to be performed to evaluate modulus of elasticity in tension with through pins and optical strain gauge. Bending experiments from proportional limit up to the rupture need to be conducted, as well as the appearance of stiffness degradation in the elastic region must be investigated. A decrease of stiffness and strength must be evaluated with cyclic loading tests.

3. Simple analytical assumptions can be used for basic calculations, but when stress concentrators, large displacements and complex stress states arise, the FEM design method must be used instead.

\section{Acknowledgements}

In accordance with the contract No. 1.2.1.1/16/A/009 between "Forest Sector Competence Centre" Ltd. and the Central Finance and Contracting Agency, concluded on 13th of October, 2016, the study has been conducted by the JSC Latvijas Finieris with support from the European Regional Development Fund (ERDF) within the framework of the project "Forest Sector Competence Centre".

\section{References}

1. Jansons, Ā., Gailis, A., \& Donis, J. (2011). Profitability of silver birch (Betula Pendula Roth.) breeding in Latvia. In Research for Rural Development 2011, 18-20 May 2011 (pp. 33-38). Jelgava: Jelgavas tipogrāfija.

2. Labans, E., Kalnins, K., \& Bisagni C. (2017). Flexural behavior of sandwich panels with cellular wood, plywood stiffener/foam and thermoplastic composite core. Journal of Sandwich Structures \& Materials, (available online first) DOI: 10.1177/1099636217699587. 
3. Zeltiņš, P., Matisons, R., Gailis, A., Jansons, J., Katrevičs, J., \& Jansons, Ā. (2018, February). Genetic Parameters of Growth Traits and Stem Quality of Silver Birch in a Low-Density Clonal Plantation. Forests, 9(2). DOI: 10.3390/f9020052.

4. Latvian Forest Sector in facts \& figures. (2017). Riga: NGO 'Zaḷās mājas'.

5. Plywood handbook. (2017). Riga: Latvijas Finieris JSC.

6. Latvian standard. (2011). European standard: Timber structures - Structural timber and glued laminated timber - Determination of some physical and mechanical properties. LVS EN 408. Brussels.

7. Latvian standard. (2004). European standard: Timber structures - Test methods - Determination of mechanical properties of wood based panels. LVS EN 789. Brussels.

8. Latvian standard. (2009). European standard: Wood-based panels - Determination of characteristic 5-percentile values and characteristic mean values. LVS EN 1058. Brussels.

9. Bonded contact. (2017). Retrieved March 15, 2018, from: http://help.solidworks.com/2017/english/ SolidWorks/cworks/c_Bonded_Contact.htm.

10. Compatible and Incompatible mesh. (2017). Retrieved March 15, 2018, from: http://help.solidworks. com/2017/english/SolidWorks/cworks/c_Compatible_and_Incompatible_mesh.htm?id=28f9fb82381f4e3 1b10d70fc485f4fb6\#Pg0\&ProductType=\&ProductName $=$.

11. Composite Laminate as an Orthotropic Material. (2017). Retrieved March 10, 2018, from: http://help. solidworks.com/2017/english/solidworks/cworks/c_Composite_Laminate_Orthotropic_Material.htm.

12. Dassault Systemes, (2017). SolidWorks Premium with Simulation Premium package [computer software]. Waltham, Massachusetts, USA. 